\title{
MERCADO DE CELULOSE NO BRASIL E EM CINCO GRANDES PAÍSES
}

\author{
MARKET OF WOOD PULP IN BRAZIL AND OTHER BIG FIVE COUNTRIES \\ Carlos Roberto Sanquetta ${ }^{1}$, Luani Rosa de Oliveira Piva ${ }^{1}$, Mateus Niroh Inoue Sanquetta ${ }^{1}$, \\ Greyce Charllyne Benedet Maas ${ }^{1}$, Ana Paula Dalla Corte ${ }^{1}$ \\ ${ }^{1}$ Universidade Federal do Paraná, Curitiba, Paraná, Brasil - carlossanquetta@gmail.com, \\ luanipiva@yahoo.com.br, mateus.sanquetta@gmail.com,greyce.maas@gmail.com \& \\ anapaulacorte@gmail.com
}

\begin{abstract}
RESUMO
Projeta-se uma expansão do consumo mundial de papel na próxima década, de 430 para 460 Mt anuais, parte significativa a ser produzida a partir de celulose de madeira. Nesse contexto, o Brasil recentemente se tornou o líder mundial na exportação de celulose. Este estudo analisa o mercado de celulose no Brasil e em 5 outros grandes países no mercado mundial de celulose (Canadá, China, Estados Unidos, Índia e Rússia). Avalia-se a hipótese da dependência do Brasil nas exportações em relação à China e as perspectivas de seu crescimento em função da tendência de aumento no consumo per capita em países emergentes muito populosos. Os dados analisados, para o período 1961 a 2017 foram obtidos do sistema FAOSTAT (Food and Agriculture Organization of the United Nations). No período analisado o Brasil se tornou o maior exportador mundial de celulose, com 13,348 Mt.ano-1 e o segundo maior produtor, com 19,527 Mt.ano-1, em 2017. A China é, de longe, o maior importador do produto, com 21,911 Mt.ano 1. Todos os outros países estudados são importadores em menor escala, embora alguns sejam grandes produtores, como os EUA (líder mundial) e o Canadá, sendo esses os principais concorrentes do Brasil entre os países examinados. Conclui-se que o Brasil ainda tem espaço para crescer no mercado de celulose, tendo em vista as perspectivas de aumento no consumo per capita em países emergentes, como a China e a Índia.
\end{abstract}

PALAVRAS-CHAVE: Madeira, Países Emergentes, Papel, Produtos Florestais.

\section{ABSTRACT}

Paper consumption is projected to expand worldwide over the next decade, from 430 to $460 \mathrm{Mt}$ per year, a significant portion to be produced from wood pulp. In this context, Brazil has recently become the leader in pulp exports. This study analyzes the pulp market in Brazil and five other major countries in the pulp market (Canada, China, United States, India and Russia). The hypothesis of Brazil's dependence on exports in relation to China is assessed and the prospects for its growth due to the trend of increasing per capita consumption in very populous emerging countries. The data analyzed for the period 1961 to 2017 were obtained from the FAOSTAT system. In the period analyzed Brazil became the world's largest exporter of pulp with 13,348 Mt.year ${ }^{-1}$ and the second largest producer with 19,527 Mt.year ${ }^{-1}$ in 2017. China is by far the largest importer of the product with $21.911 \mathrm{Mt}$.year ${ }^{-1}$. All other countries studied are smaller-scale importers, although some are large producers, such as the US (world leader) and Canada, which are Brazil's main competitors among the countries examined. It is concluded that Brazil still has room to grow in the pulp market, given the prospects of increased per capita consumption in emerging countries such as China and India.

KEYWORDS: Wood, Emerging Countries, Paper, Forest Products 


\section{INTRODUÇÃO}

A renda média per capita mundial elevou-se de US\$ 694, em 1970, para US\$ 8.826, em 2017, (BANCO MUNDIAL, 2019a). Esse aumento no poder aquisitivo, juntamente com a globalização, trouxera para várias regiões do globo uma nova perspectiva de consumo, o que repercutiu também no consumo de papeis pelas pessoas. Esse processo se revelou marcante em países emergentes, como o Brasil e a China, entre outros.

Nas últimas décadas o Brasil se preparou para ter maior projeção na produção mundial de celulose, a matéria prima básica para a produção de papeis. O país atualmente figura entre aqueles com as maiores áreas de florestas plantadas destinadas à produção de celulose e papel (FAO, 2015; IBÁ, 2018; SANQUETTA et al., 2018). Para alavancar a sua produção, foram realizados investimentos no plantio de florestas plantadas e na indústria, os quais atingiram cerca de $R \$$ 6,5 bilhões em 2018, dos quais $R \$ 3,2$ bilhões em manejo das florestas e $\mathrm{R} \$ 3,5$ bilhões no parque fabril. Com isso, a produção industrial alcançou a marca de 19,5 Mt de celulose e 10,5 Mt de papeis (IBÁ, 2018).

$A$ produção de celulose no Brasil é impulsionada pelas exportações. A Europa e a China são os destinos mais relevantes do mais competitivo produto brasileiro nesse segmento: a celulose branqueada de eucalipto é o principal vetor exportações brasileiras de celulose e papel, embora outros produtos também tenham relevância. $\mathrm{O}$ aumento dos volumes exportados nos últimos anos decorre do maior consumo de produtos outrora menos consumidos pelos emergentes, sobretudo na China. Este estudo pretende demonstrar essa tese.

O aumento do consumo nos grandes países emergentes deverá continuar sendo o motor das exportações e do crescimento do setor de celulose e papel no Brasil nos próximos anos. Os mercados dos países desenvolvidos têm reduzido seu consumo de celulose nas últimas décadas, ou na melhor das hipóteses mantido seus patamares históricos. Isso demostra a preocupação do setor ao direcionar seus esforços mercadológicos com vistas a manter seu posicionamento e abrir e/ou se consolidar no mercado. Isto posto, para qual mercado o Brasil deve apontar? Manter sua posição no mercado chinês, apostar na Índia ou enxergar outras possibilidades?

De outro lado, como fica a produção, exportação e importação de grandes e tradicionais países que atuam nesse mercado, como os EUA e o Canadá? Qual a capacidade de o Brasil se tornar o maior produtor mundial de celulose? O que é necessário para atingir isso?

A plataforma FAOSTAT (FAO, 2019) organiza, sintetiza e dissemina dados brutos de produção, exportação e importação de produtos florestais de muitos países, inclusive do Brasil. Todavia, essas informações foram pouco exploradas cientificamente (SANQUETTA et al., 2019). Não existem publicações científicas que mostrem a dinâmica da produção e do mercado de celulose em longo espectro temporal. Ademais, comparações e paralelos entre países inexistem.

Devido à carência de publicações, existem importantes hipóteses científicas ainda não puderam ser testadas. Então, este trabalho testa a dependência das exportações brasileiras de celulose do Brasil em relação às importações da China e as perspectivas de aumento de sua participação em mercados ainda pouco explorados. O objetivo deste estudo foi analisar a produção, importação, exportação e consumo aparente de celulose em um horizonte temporal de 56 anos (1961 a 2017) em 6 grandes países, desde que foi iniciada a série produzida pela FAO.

\section{MATERIAL E MÉTODOS}

Os dados empregados neste estudo foram obtidos diretamente do sistema FAOSTAT disponível no site da FAO (http://www.fao.org/faostat/en/\#home) (FAO, 2019). Os dados contêm registros de produção, importação e exportação de diferentes tipos de celulose (química, semiquímica e mecânica) de muitos países. Neste trabalho foram analisados, além do Brasil, dados de 5 grandes países, do ponto de vista territorial e/ou populacional, além de configurarem-se como importadores de celulose brasileira. São esses: Canadá, China, EUA, Índia e Rússia.

A partir dos dados de produção, importação e exportação, foi realizado o cálculo do consumo aparente anual de 1961 a 2017, utilizando-se a seguinte fórmula:

$C A(i)=P(i)+I(i)-E(i)$

Em que: $C A(i)=$ consumo aparente dos papeis no ano $\mathrm{i}[\mathrm{t}]$; $P(i)=$ produção no ano $i[\mathrm{t}] ; E(i)=$ exportação no ano $i[\mathrm{t}] ;$ $I(i)=$ importação no ano $i[\mathrm{t}]$.

Para o cálculo do consumo anual per capita (equação 2) foram utilizados dados populacionais dos seis países a partir do site do Banco Mundial (BANCO MUNDIAL, 2019b):

$\operatorname{CApc}(i)=\left(\frac{C A(i)}{\operatorname{Pop}(i)}\right) / 1000$

Em que: $C A p c(i)=$ consumo aparente per capita dos celulose no ano $i\left[\mathrm{~kg} \cdot \mathrm{hab}^{-1}\right.$ ]; $\operatorname{Pop}(i)=$ população do país no ano $i$ [no de habitantes].

Os dados da Rússia estavam disponíveis somente a 
partir de 1992. Portanto, neste estudo a representação daquele país ficou parcialmente prejudicada. Para os demais países a série completa permitiu análises mais completas e abrangentes.

\section{RESULTADOS}

\section{Produção}

No período analisado, os seis países produziram um total de 4,578 bilhões de toneladas de celulose, dos quais $74,13 \%$ por meio de processos químicos, 7,70\% por processos semi-químicos e $18,53 \%$ por processos mecânicos. Em 2017 esses percentuais encontravam-se em $80,73 \%, 6,74 \%$ e 12,53 , respectivamente. Portanto, evidencia-se um aumento da participação da celulose química em detrimento das demais, o que demonstra a mudança no perfil tecnológico de produção (Figura 1).

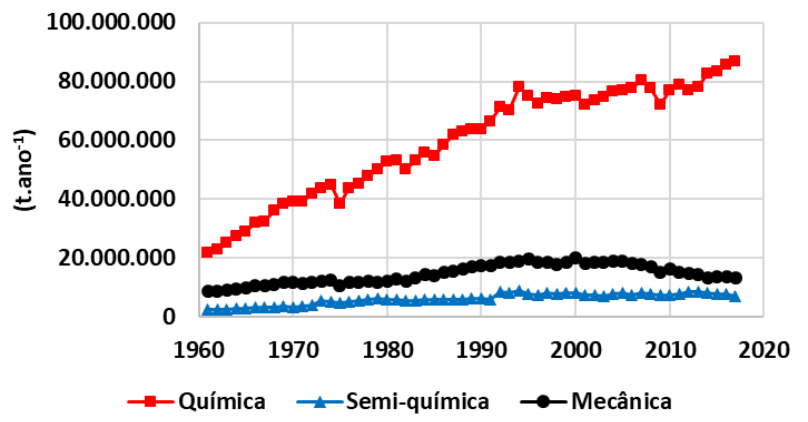

Figura 1. Produção de celulose em seis grandes países do mundo no período de 1961 a 2017. Fonte: adaptado de FAO (2019).

Desde o início da série temporal da FAO, os EUA sempre foram os maiores produtores de celulose no mundo. $O$ segundo posto historicamente pertenceu ao Canadá, que foi ultrapassado pelo Brasil pela primeira vez em 2015. Em quarto lugar vem a China, que já ameaça a posição do Canadá, sendo esses seguidos por Rússia e Índia (Figura 2).

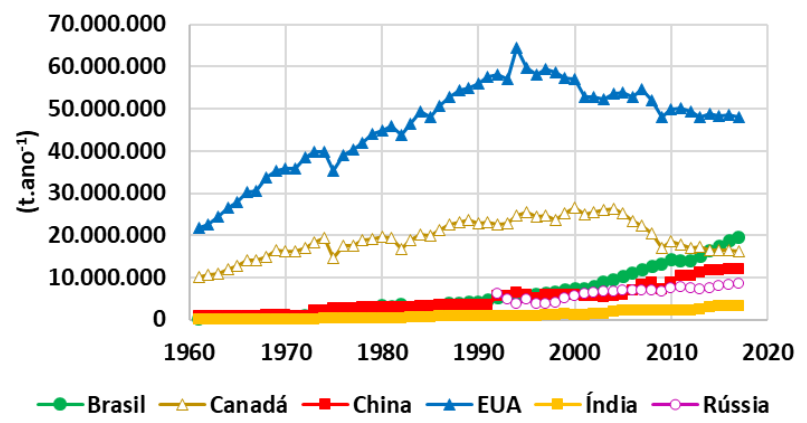

Figura 2. Produção de celulose por país no período de 1961 a 2017. Fonte: adaptado de FAO (2019).

A produção americana apresentou ascensão até 1994, quando começou a declinar drasticamente. Fato similar ocorre com o Canadá, que apresentou uma forte redução na sua produção de celulose por volta do ano 2005. Brasil e China aumentaram muito a sua produção do produto, sobretudo na última década. Rússia e Índia também tiveram aumento na sua produção, porém em menor escala quando comparados a Brasil e China.

Em 2017, os EUA representavam 44,63\% da produção de celulose nesses 6 grandes países, seguidos por Brasil com 18,16\%, Canadá com 15,16\%, China com 11,22\%, Rússia com 7,95\% e Índia com 2,89\%. Ainda existe uma enorme diferença entre o nível de produção americana e a brasileira, mas se somadas as produções dos BRICS (Brasil, Rússia, Índia e China - excluindo-se aqui a África do Sul), estas se aproximam da produção americana. Isso mostra que o eixo de produção de celulose no mundo move-se das economias desenvolvidas rumo às emergentes.

\section{Importação}

A importação acumulada de celulose no período de 56 anos dos países analisados foi de 665,381 giga toneladas (Gt, que equivale a $\mathrm{t} * 10^{9}$ ), estando atualmente no patamar anual de 37,212 Gt (base 2017). O maior importador é a China, com 21,911 Gt importadas em 2017, o que representa $58,88 \%$ do montante adquirido pelos países no referido ano.

Em sequência vêm Rússia, com 22,97\% (8,547 Gt), EUA com 14,13\% (5,259 Gt), Índia com 2,04\% (760 M t), Canadá com 1,40\% (522 Mt) e, por último, o Brasil com 0,57\%, ou seja, 212 Mt (base 2017). Portanto, os quatro países do BRICS somam mais de $84 \%$ do montante importado de celulose em 2017, contudo o Brasil e a Índia são importadores em pequena escala (Figura 3).

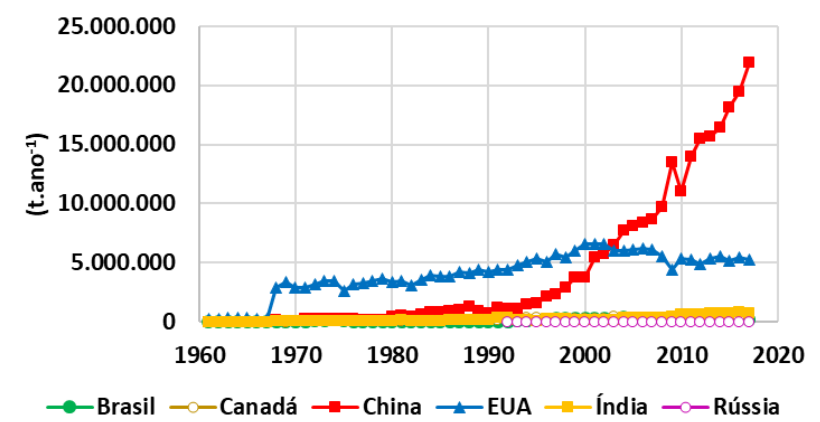

Figura 3. Importação de celulose por país no período de 1961 a 2017. Fonte: adaptado de FAO (2019).

O produto de maior importação pelos países considerados, historicamente (ao longo de todo o período considerado) é de celulose química, com $87 \%$ e, atualmente (2017), com $86 \%$. As celuloses semi-química e 
mecânica representam de 6 a $7 \%$ do volume comercializado, tanto historicamente como na atualidade.

\section{Exportação}

As exportações de celulose dos 6 países estudados atingiram $80,514 \mathrm{Gt}$ no período, sendo $91,86 \%$ de celulose química, 6,20 de semi-química e 1,94 de mecânica. Em 2017 esses valores pouco se alteraram, com um leve aumento da participação da celulose química nas transações.

O maior exportador na atualidade é o Brasil, com 13,349 Gt movimentados em 2017, o que corresponde a $35,87 \%$ das exportações do produto pelos 6 países analisados. Canadá e EUA também são grandes exportadores, com 9,472 Gt e 7,051 Gt, respectivamente. Somadas as exportações de Brasil, Canadá e EUA representam cerca de $87 \%$ do volume movimentado pelos 6 países. A Rússia exportou em 2017 o total de 2,258 Gt, o que corresponde a $6,98 \%$ da soma das exportações dos países considerados. China e Índia têm exportações pouco expressivas (Figura 4).

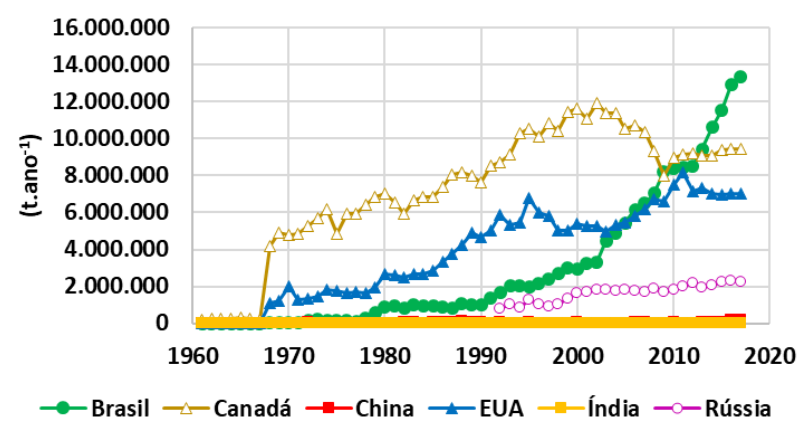

Figura 4. Exportação de celulose por país no período de 1961 a 2017. Fonte: adaptado de FAO (2019).

É destacada a trajetória do Brasil nas exportações de celulose, que em 2006 ultrapassou os EUA e em 2014 sobrepujou o Canadá, tornando-se o maior exportador mundial. Das exportações brasileiras na atualidade, quase $100 \%$ são de celulose química, notadamente de eucalipto.

\section{Consumo Aparente}

No período analisado, foram consumidos 4,393 Tt de celulose pelos 6 países analisados. Em 2017, o nível de consumo desses países era de $112,393 \mathrm{Gt}$, o que excede a produção nesses países.

Os maiores consumidores em 2017 são os EUA, com 46 Gt, ou $41,10 \%$ do consumo aparente nos 6 países pesquisados, seguidos pela China, com 33,758 Gt, correspondentes a 30,04\%. Em menor escala vêm Rússia com consumo de 14,835 Gt (13,20\%), Canadá com 7,348 Gt $(6,54 \%)$, Brasil com 6,390 Gt $(5,69 \%)$ e por último a Índia com $3,863 \mathrm{Gt}(3,44 \%)$. Os países do BRICS consumiram em 2017 o total de $54,848 \mathrm{Gt}$, o que corresponde à $52,36 \%$ da soma dos 6 países analisados (Figura 5).

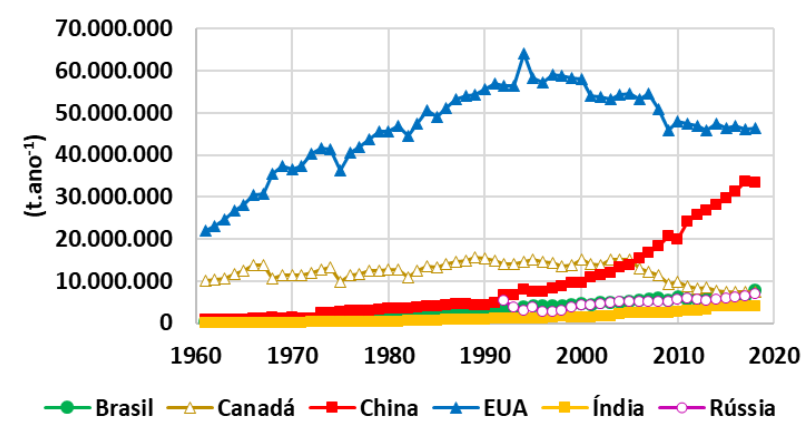

Figura 5. Consumo aparente de celulose por país no período de 1961 a 2017.

O consumo per capita também foi analisado, o que reflete, em grande parte, à produção de papel em cada país, pois a celulose consumida domesticamente, na sua maioria, é usada para esse fim (Figura 6).

O maior consumo aparente per capita de celulose entre os países estudados verifica-se no Canadá, com 200,64 kg.ano ${ }^{-1}$, seguido dos EUA, com 142,38 kg.ano ${ }^{-1}$ e da Rússia, que tem um consumo de $100,03 \mathrm{~kg} \cdot \mathrm{ano}^{-1}$. Os três países emergentes, Brasil, China e Índia, apresentam consumos per capita muito inferiores, quais sejam: 30,98; 23,43 e 2,88 kg.ano ${ }^{-1}$, respectivamente (Figura 6).

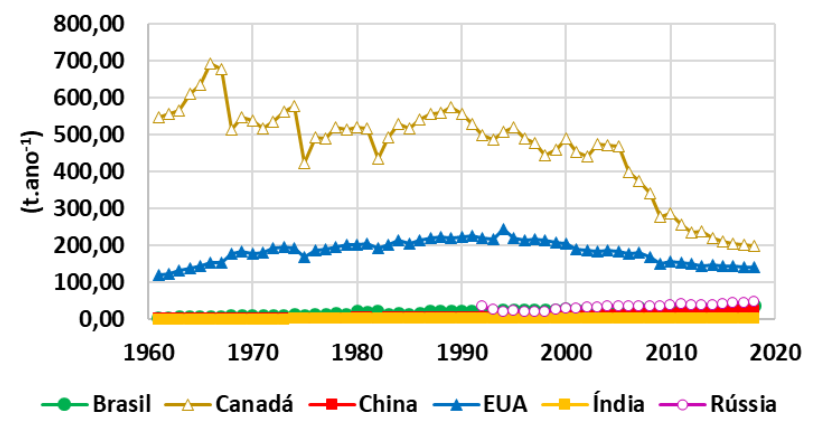

Figura 6. Consumo aparente per capita de celulose por país no período de 1961 a 2017.

É importante destacar o forte aumento do consumo de celulose na China, o qual se iniciou nos últimos 20 anos. A persistir a tendência atual é muito provável que o consumo da China supere o dos EUA em menos de uma década.

Observa-se que entre os países do BRICS há diferenças marcantes em termos de evolução temporal do consumo de celulose. A Rússia, depois de passar por um período de declínio no consumo na década de 1990, possivelmente 
em decorrência da queda do regime soviético, passa a ter um crescimento contínuo até os dias de hoje (Figura 7).

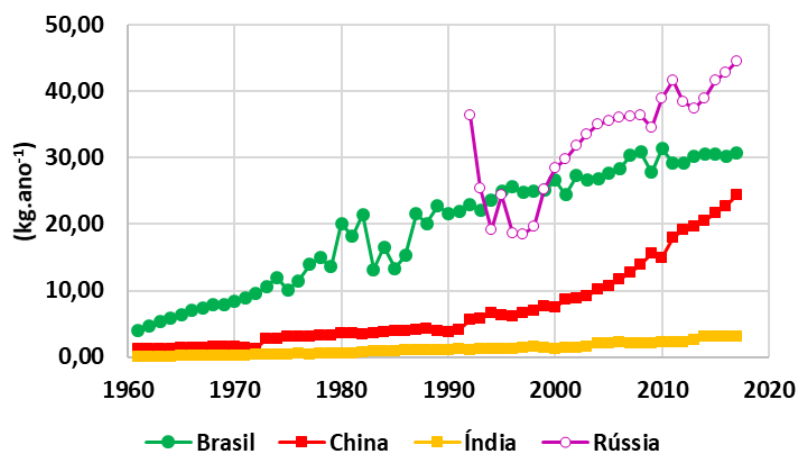

Figura 7. Consumo aparente per capita de celulose nos países do BRICS no período de 1961 a 2017.

O Brasil, por sua vez, vem apresentando uma trajetória de crescimento contínuo, com alguns períodos curtos de queda no consumo. A China, embora tenha atualmente um consumo per capita similar ao do Brasil, experimentou uma aceleração mais muito expressiva a partir de meados da década de 1990. Considerando essa tendência, a China deve ultrapassar o Brasil em termos de consumo per capita já nos próximos anos.

A Índia teve um expressivo crescimento em seu consumo per capita de celulose no período, mas ainda seu nível é muito inferior a todos os demais países analisados.

\section{DISCUSSÃO}

Os eixos de produção, importação, exportação e consumo de celulose mudaram no período de 56 anos, com destaque para o Brasil na produção e exportação e da China nas importações. O Brasil caminha para ser o maior produtor mundial e, atualmente, já é o maior exportador. A China passou a ser o maior importador em algumas décadas. Enquanto os consumos totais e per capita caem nos EUA e Canadá, estes sobem nos países do BRICS. Entretanto, os consumos per capita de EUA e Canadá ainda são muito superiores àquelas dos países do BRICS, especialmente no Brasil, China e Índia.

As exportações brasileiras de celulose são altamente dependentes das importações da China (Figura 8). O vertiginoso crescimento das exportações pelo Brasil nesse segmento depende atualmente do consumo na China e, por conseguinte, do desempenho de sua economia. A economia chinesa, que cresceu a dois dígitos na década passada, provavelmente não deverá um crescimento de PIB superior a 3\% na próxima década (OECD, 2019). Isso é preocupante para o mercado brasileiro de celulose, na medida que as perspectivas futuras alimentam os investimentos e as expansões nesse setor.

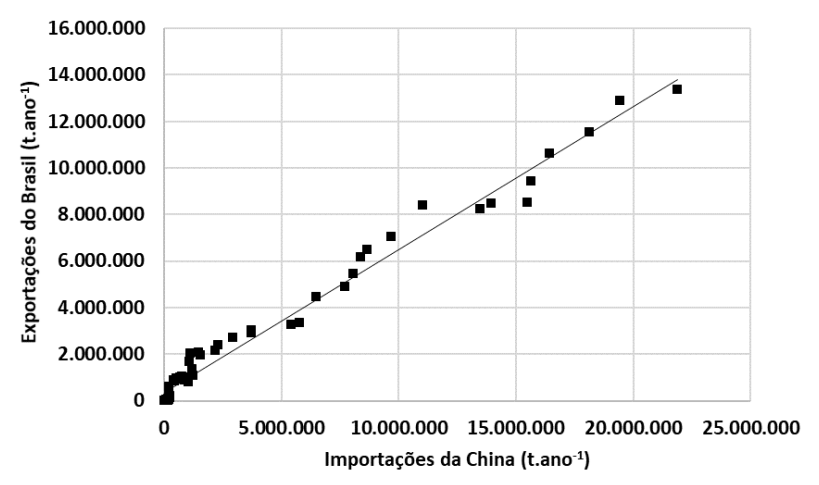

Figura 8. Relação entre as importações chinesas e as exportações brasileiras de celulose no período de 1961 a 2017.

Existe uma corrente contrária que crê que as reformas estruturais conduzidas pelo governo chinês poderão impulsionar a sua economia e manter a taxa de crescimento de longo prazo a patamares de 6,5\% (LIN, 2019). Entretanto, a guerra comercial China-EUA e o alto nível de endividamento das empresas e dos governos locais estão entre as principais incertezas da economia chinesa (QIAN, 2019). Esses elementos poderão também definir o alcance da expansão das exportações brasileiras de celulose na próxima década.

Para atingir esse patamar, é importante que o setor de celulose do Brasil encontre meios de para diminuir a demasiada dependência da China, mesmo que haja espaço para crescimento naquele país, tendo em vista que o seu consumo per capita de celulose está em patamar muito aquém das economias desenvolvidas.

Nesse contexto, outros países emergentes grandes e populosos, como a Índia, poderão representar a diferença. O crescimento do PIB previsto para a Índia é maior que o da China, principalmente na próxima década, ficando na casa de 5 a 7\% (OECD, 2019). Ademais, o consumo per capita de celulose na Índia ainda é muito baixo, entretanto tem todas as condições de apresentar forte crescimento nos próximos anos. O mesmo pode ocorrer em países como Paquistão, Bangladesh, Nigéria e Indonésia, por exemplo

A participação da Índia na demanda global de papel está crescendo gradualmente, à medida que a demanda doméstica está aumentando a um ritmo constante, enquanto a demanda nos países ocidentais está se contraindo. A demanda doméstica na Índia cresceu de 9,3 Mt no ano de 2008 para 15,3 Mt em 2016, a uma taxa de $6,4 \%$. Apesar do crescimento sustentado observado pela indústria, o consumo de papel per capita na Índia é de pouco mais de $13 \mathrm{~kg}$, muito abaixo da média global de 57 
kg e significativamente abaixo de $200 \mathrm{~kg}$, a média de consumo na América do Norte (CARE RATINGS, 2018).

Assim, é provável, no curto prazo o Brasil ainda dependerá muito da China para poder exportar celulose em larga escala, mas tem espaço para crescer no mercado, tendo em vista as perspectivas de aumento no consumo per capita nesses dois países emergentes e em outros já citados.

De acordo com o BNDES (2017), as empresas brasileiras produtoras de celulose são referência em relação às melhores práticas internacionais. Elas têm como principais forças: uma base florestal altamente produtiva e integrada à indústria; a elevada escala produtiva e baixa idade tecnológica das plantas industriais; e equipes qualificadas em P\&D florestal. Porém, assevera as principais fraquezas como sendo: a dependência de um único produto (celulose de fibra curta de eucalipto); foco no mercado externo, fazendo com que o preço da celulose e o câmbio tenham grande efeito no seu retorno; longa distância para os principais mercados consumidores; e pouca expertise em P\&D industrial.

Deste modo, para poder manter sua competitividade e galgar posição mais destacada nesse mercado, o Brasil precisa melhorar sua eficiência e otimizar seus processos. Além disso precisa se preparar estrategicamente para um novo patamar de consumo de madeira, com a ampliação de sua base florestal.

\section{CONCLUSÕES}

A produção de celulose nos em quatro dos seis países estudados no período de 56 anos. Nos EUA e no Canadá isso não ocorreu;

O Brasil é a ser o maior exportador e a China o maior importador de celulose entre os países analisados;

O Brasil apresenta forte dependência da China nas suas exportações de celulose;

Existe espaço para crescimento das exportações brasileiras de celulose nos próximos anos em função da perspectiva de aumento no consumo per capita nos países emergentes, como a China e a Índia.

\section{AGRADECIMENTOS}

À FAO pelo acesso aos dados.

\section{REFERÊNCIAS}

BANCO MUNDIAL. Adjusted net national income per capita (current US\$). 2019a. Disponível em: https://data.worldbank. org/indicator/NY.ADJ.NNTY.PC.CD?end=2017\&start=1970\&view =chart

BANCO MUNDIAL. Population, total. 2019b. Disponível em: https://data. worldbank.org/indicator/SP.POP.TOTL?end=2017\& start=1970\&view=chart

BNDES - Banco Nacional de Desenvolvimento Econômico e Social. Panoramas Setoriais 2030: Papel e Celulose. Hora, A. B. (editor). 2017. Disponível em: https://web.bndes.gov.br/bib/jspui/ bitstream/1408/15402/1/4\%20Panorama\%20Setorial Setor\%20 Florestal\%2C\%20Celulose\%20e\%20Papel P.pdf

CARE RATINGS. Indian Paper Industry. Industry Research. February 12th, 2018. Disponível em: http://www.careratings. com/upload/NewsFiles/Studies/Paper\%20Industry\%20Report\%2 02018.pdf

FAO - Food and Agriculture Organization of the United Nations. Global Forest Resources Assessment 2015. Rome: 2015. Disponível em: http://www.fao.org/3/a-i4808e.pdf

FAO - Food and Agriculture Organization of the United Nations. FAOSTAT. 2019. Disponível em: http://www.fao.org/faostat/ en/\#data/GF

IBÁ - INSTITUTO BRASILEIRO DE ÁRVORES. Relatório 2017. São Paulo: IBÁ, 2018.

LIN, J.Y. China's growth deceleration: causes and future growth prospect. Frontiers of Economics in China, v.14, n.1, p.26-52. 2019. Disponível em: http://journal.hep.com.cn/fec/EN/ 10.3868/s060-008-019-0003-1

OECD - ORGANIZAÇÃO PARA A COOPERAÇÃO E DESENVOLVIMENTO ECONÔMICA. China GDP growth forecast 2019-2024 and up to 2060, data and charts. 2019a. Disponível em: https://pt.knoema.com/logqwx/china-gdp-growth-forecast2019-2024-and-up-to-2060-data-and-charts

OECD - ORGANIZAÇÃO PARA A COOPERAÇÃO E DESENVOLVIMENTO ECONÔMICA. India GDP growth forecast 2019-2024 and up to 2060, data and charts. 2019b. Disponível em: https://pt.knoema.com/xxnxggb/india-gdp-growth-forecast2019-2024-and-up-to-2060-data-and-charts

QIAN, J. Chinese Economy 2018: transforming economic structures and stabilising growth. East Asian Policy, v.11, n.1, p.14-32, 2019. Disponível em: https://www.worldscientific.com/ doi/abs/10.1142/S1793930519000023

SANQUETTA, C.R. et al. Dinâmica em superfície, volume, biomassa e carbono nas florestas plantadas brasileiras: 19902016. BIOFIX Scientific Journal, v.3 n.1 p.152-160, 2018a. Disponível em: http://dx.doi.org/10.5380/biofix.v3i1.58384

SANQUETTA, C.R. et al. Produção, importação, exportação e consumo aparente de painéis de madeira no Brasil entre 1961 e 2016. BIOFIX Scientific Journal, v.5, n.1, p.44-49, 2019. Disponível em: https://revistas.ufpr.br/biofix/article/view/66112/39173

Recebido em 25-11-2019 Aceito em 27-01-2020 